\title{
In Vitro Antifungal Activity of Some Indigenous Medicinal Plant Extracts against Five Isolates of Aspergillus fumigatus
}

\author{
EMAN F. SHARAF ${ }^{1 *}$ AND HANAN S. AL-ZAIDI ${ }^{1}$ \\ Department of Botany and Microbiology, Faculty of Science, Cairo University, Giza 12511, Egypt, ${ }^{1}$ Department of Biology, \\ College of Science, Taibah University, Al-Madinah Al-Munawarah 41412, Kingdom of Saudi Arabia
}

\section{Sharaf et al.: Antifungal Activity of Medicinal Plant Extracts against Aspergillus fumigatus}

\begin{abstract}
There is a constant exposure of humans to Aspergillus mold fungus and $95 \%$ of the pathogenic species. It is important to study drugs with new efficacy against infections because of increased prevalence of infections resistant to antibiotics. The present study aims to assess the antifungal activity of aqueous and ethanol plant extracts (cinnamon, garlic, ginger and guava) against five isolates of the opportunistic mold Aspergillus fumigatus. The results showed that effect of ethanol and aqueous extracts of cinnamon was same on all the five isolates of Aspergillus fumigatus. The recorded diameters of inhibition zone for isolates $1,2,3,4$ and 5 exerted by the cinnamon ethanol extracts were 41, 46, 40, 45 and $46 \mathrm{~mm}$ respectively. Moreover, ginger was excluded in next experiments because all the isolates showed resistance against the aqueous and ethanol extract of ginger, except for isolate 5. Minimum inhibitory concentration was $2 \mathbf{~ m g} / \mathbf{m l}$ ethanol extract of garlic and cinnamon whereas that of aqueous extract of garlic and cinnamon was $40 \mathrm{mg} / \mathrm{ml}$ and $10 \mathrm{mg} / \mathrm{ml}$, respectively. The study concluded that ethanol extract of cinnamon can be used as antimycotic agent against Aspergillus fumigatus to treat diseases but it is urged to detect the sensitivity of fungal isolate to the extract before using as different responses are provided by isolates in a wide range of extracts.
\end{abstract}

Key words: Antifungal activity, Aspergillus fumigatus, plant extracts, aspergillosis, toxicogenic

Aspergillus fumigatus (A. fumigatus) is a known fungus belonging to genus Aspergillus. This fungus results in the development of certain disease among the immune compromised individuals and cause allergic reactions ${ }^{[1]}$. The infection caused by $A$. fumigatus is called aspergillosis that is a life threatening fungal infection ${ }^{[2]}$. Thousands of minute grey-green conidia are produced in fungal colonies from the conidiophores that may become airborne ${ }^{[3]}$. These spores are present in the atmosphere and can be inhaled. There is increased occurrence of $A$. fumigatus among the poultry flocks causing mild or even severe forms of diseases, which results in greater economic losses. The severity of infection outcome depends on the hygienic conditions and immune system of different animals ${ }^{[4]}$. The concentration of fungal spores and bacteria is likely to increase in the atmosphere as a result of warm temperature, degraded litters, poor ventilation, long-term feed storage and excessive ammonia and moisture ${ }^{[5,6]}$.

*Address for correspondence

E-mail: emanfsharaf@yahoo.com

July-August 2021
The broad spectrum of diseases caused by the members of genus Aspergillus are encompassed as aspergillosis, which develop as a result of contaminated intra-hospital environments, direct inoculation through surgical tools, inhalation of toxic compounds, air conditioners and mechanical ventilation ${ }^{[7,8]}$. It has been shown that the antifungal drugs that are used currently are only partially effective in treating the infection ${ }^{[9]}$. There is increase in the appearance of Aspergillus strains in the hospital settings ${ }^{[10,11]}$. There is need to identify new targets and develop new antifungal agents as therapeutic alternatives that would be effective antifungal agents ${ }^{[12]}$.

The medicinal plants containing active cheap constituents are economic and useful in treating much

\footnotetext{
This is an open access article distributed under the terms of the Creative Commons Attribution-NonCommercial-ShareAlike 3.0 License, which allows others to remix, tweak, and build upon the work non-commercially, as long as the author is credited and the new creations are licensed under the identical terms
} Indian J Pharm Sci 2021;83(4):695-700 
human-related disease ${ }^{[13,14]}$. The oil of four Iranian herbs including, Thymus daenensis var daenensis Celak, Zataria multiflora Boiss, Thymbra spicata var. spicata L. and Bunium persicum (Boiss) for antifungal activity against $A$. niger, A. fumigatus, A. flavus and A. parasiticus was investigated by Pirbalouti et al. ${ }^{[15]}$. The results showed that the oils from Thymus daenensis and Thymbra spicata are likely to be used as natural antifungals for preserving food and health of humans. Another study conducted by Mann et al. ${ }^{[16]}$ showed that aqueous root extracts of Anogeissus leiocarpus and Terminalia avicennioides inhibit the growth of the all tested organisms. Moreover, the minimum fungicidal concentration (MFC) ranged between 0.04 and $0.08 \mu \mathrm{g} / \mathrm{ml}$; while, minimum inhibitory concentration (MIC) of the extracts ranged between 0.03 and $0.07 \mu \mathrm{g} / \mathrm{ml}$. A large growth inhibition zone was developed by Carmo et al. ${ }^{[17]}$ as he reported strong antifungal activity and growth inhibition for Cinnamomum zeylanicum (C. zeylanicum) on the growth and morphogenesis of some potentially pathogenic Aspergillus species. the decreased conidiation, loss of pigmentation, cytoplasm leakage and disrupted cell structure are the major morphological changes observed as a result of degradation of the fungal wall. Therefore, Carmo et al. ${ }^{[17]}$ concluded that protection against growth of Aspergillus species could be provided by $C$. zeylanicum essential oil as it works as potential antifungal compound.

The health of individuals is significantly affected as a result of increased prevalence of drug resistance among the infectious agents. Doust et al. ${ }^{[18]}$ demonstrated the incidence and spread of drug resistance among various agents including fungi. Nowadays, conducting research on drugs with new efficacy against infections is important because of increased in the infections resistant to antibiotics ${ }^{[19,20]}$. Humans are constantly exposed to Aspergillus mold fungus and $95 \%$ of the pathogenic species include three species of Aspergillus including A. fumigatus, A. flavus and A. niger ${ }^{[21]}$. These species may cause local infections in different body organs like lungs and sinuses, no matter how healthy an individual is ${ }^{[22]}$. Moreover, this infection can result in severe consequences among individuals with deficient immune systems. None of the previous studies have elucidated effect of the most potent natural antifungal plant extract on some growth criteria of A. fumigatus. Therefore, the present study aims to assess the antifungal activity of ethanol plant extracts against the opportunistic mold $A$. fumigatus.

\section{MATERIALS AND METHODS}

The fresh plant samples including ginger, garlic, cinnamon sticks and guava leaves used in this study were purchased from Al-Madinah local market. Five isolates of $A$. fumigatus were obtained from the Microbiological Laboratory of the Department of Biology, Taibah University. A. fumigatus isolates were confirmed by Raper \& Fennell ${ }^{[23]}$ and El-Shafie ${ }^{[24]}$ to belong to genus Aspergillus.

\section{Culture medium:}

The culture medium that is Czapek Dox's agar medium used in this study comprises of following constituents: $20 \mathrm{~g} / \mathrm{l}$ sucrose; $3 \mathrm{~g} / \mathrm{l}$ sodium nitrate $\left(\mathrm{NaNO}_{3}\right)$; $1 \mathrm{~g} / \mathrm{l}$ potassium dihydrogen phosphate $\left(\mathrm{KH}_{2} \mathrm{PO}_{4}\right)$; $0.5 \mathrm{~g} / \mathrm{l}$ magnesium sulfate heptahydrate $\left(\mathrm{MgSO}_{4} 7 \mathrm{H}_{2} \mathrm{O}\right)$; $0.5 \mathrm{~g} / 1$ potassium chloride $(\mathrm{KCl}) ; 0.05 \mathrm{~g} / 1$ ferrous sulfate pentahydrate $\left(\mathrm{FeSO}_{4} .5 \mathrm{H}_{2} \mathrm{O}\right) ; 20 \mathrm{~g} / 1$ agar; 11 distilled water.

\section{Preparing plant extracts:}

The fresh plant samples were washed, sterilized, cut and dried at room temperature. The dried form of plant extracts was converted into fine dry powder in electric grinder. The hot aqueous extract was prepared by soaking $20 \mathrm{~g}$ of plant powder in $100 \mathrm{ml}$ distilled water and the mixture was left at $60^{\circ}$ in water bath, for $30 \mathrm{~min}$. Whereas, ethanol extract was prepared according to Varghese ${ }^{[25]}$ method by adding $20 \mathrm{~g}$ of plant powder to $100 \mathrm{ml}$ of $95 \%$ ethanol and left overnight then filtered. The produced filtrate was of $20 \%(\mathrm{w} / \mathrm{v})$ concentration $(200 \mathrm{mg} / \mathrm{ml})$. The suspension was centrifuged at $5000 \mathrm{rpm}$ for $10 \mathrm{~min}$ and filtered through a Whatman No .1 filter paper. The supernatant fluid was allowed to evaporate under pressure through the rotary evaporator apparatus. The concentrated organic solvent extracts were dissolved in $10 \%$ dimethyl sulfoxide (DMSO) and kept at $-20^{\circ[26]}$.

\section{Antifungal activity:}

The agar well diffusion method proposed by Hadacek et $a l .{ }^{[27]}$ was used to carry out the inhibitory activity of plant extracts. The plates (triplicates) were seeded with $1 \mathrm{ml}$ of fungal homogenous spore suspension of $5 \mathrm{~d}$ old culture and after inoculum absorption wells were made using sterile cork borer ( $9 \mathrm{~mm}$ diameter) then $100 \mu \mathrm{l}$ of the extracts were introduced into each well. The plates were left for $30 \mathrm{~min}$ for better absorption. Later, the plates were incubated at $28^{\circ}$ for $48 \mathrm{~h}$. Control was conducted using either sterile distilled water or 
DMSO. Measurement was obtained for the diameter of the produced inhibition zones after subtraction of control value and taken as a criterion for the inhibitory activity.

\section{Extraction using different organic solvents:}

Different solvents were prepared ${ }^{[25]}$ and tested to obtain the best one for extraction, because of increased higher antifungal activity of aqueous and ethanolic extract of the tested plants against isolate 2 of $A$. fumigatus. Antimicrobial activity of the prepared plant extracts was tested against isolate 2 of $A$. fumigatus. Control was conducted with each solvent separately and means were calculated after subtraction of control value (DMSO). Aqueous and ethanol cinnamon and garlic extracts were chosen for the next experiments as they helped in achieving the most potent antimicrobial activity.

\section{Determining MIC:}

MIC was determined using different concentrations of either ethanol extract or hot water extract of both cinnamon and garlic as explained by Gayoso et al. ${ }^{[28]}$.

\section{Data analysis:}

The data was added and analyzed using Statistical package of social sciences (SPSS). Analysis of variance (ANOVA) was used to determine the significant differences.

\section{RESULTS AND DISCUSSION}

Table 1 shows the antifungal activities of four plant extracts selected in the present study. Significant variation of inhibition was exerted by the plant extracts on the growth of five isolates of $A$. fumigatus $(\mathrm{p} \leq 0.05$ ). Isolates 1 and 2 were affected by the ethanol extract of guava leaves, with $36 \mathrm{~mm}$ and $30 \mathrm{~mm}$ of inhibition zone diameters, respectively. However, isolate 1 was affected by hot water extract with inhibition zone diameter of $40 \mathrm{~mm}$. The effect of ethanol and aqueous extracts of cinnamon was same on all the five isolates of A. fumigatus.

For isolates 1 to 5, the recorded diameters of inhibition zone exerted by the cinnamon ethanol extract were 41, 46, 40, 45 and $46 \mathrm{~mm}$ respectively. As compared to the ethanol extract of cinnamon, the aqueous extract of cinnamon was less effective and the diameter of inhibition zone of isolates 1, 2, 3 and 4 were 20, 23, 21 and $19 \mathrm{~mm}$ respectively. There was no impact of aqueous extract of cinnamon on isolate 5. Inhibition effect against isolates 2, 3 and 5 was shown in the presence of aqueous extract of garlic; however, other isolates showed resistance against the aqueous extract of garlic. On the contrary, the ethanol extract of garlic was able to exert its effects in isolates 1 and 2 (inhibition diameter was 20 and $44 \mathrm{~mm}$, respectively). In the similar context, ginger was excluded in next experiments because all the isolates showed resistance against the aqueous and ethanol extract of ginger, except for isolate 5. Isolate 5 was weakly affected by aqueous extract of ginger with $15 \mathrm{~mm}$ diameter of inhibition zone.

Different solvents were tested for selecting the most effective one because the ethanol extract of all the tested plant extracts was inhibitory to the most sensitive isolate 2 (Table 2), except for ginger. Therefore, the best solvent for extraction was ethanol, as it exerted significant inhibitory activity $(\mathrm{p} \leq 0.05)$, as compared to methanol, ethyl acetate and chloroform. Moreover, there was significant effectiveness of ethanol extract of garlic and cinnamon, as compared to the guava extracts. However, there was no impact of chloroform extract of guava leaves on isolate 2 of $A$. fumigatus.

The results demonstrate that cinnamon and garlic different solvent extracts showed the prominent antifungal activity against isolate 2 of $A$. fumigatus

TABLE 1: ANTIFUNGAL ACTIVITY OF THE TESTED PLANT EXTRACTS AGAINST A. fumigatus ISOLATES EXPRESSED AS DIAMETER OF INHIBITION ZONE (mm)

Diameter of inhibition zone $(\mathrm{mm})$

A. fumigatus isolates $\quad$ Plant extracts

\begin{tabular}{|c|c|c|c|c|c|c|c|c|}
\hline \multirow[t]{2}{*}{ A. Jumingulus isolates } & \multicolumn{2}{|c|}{ Guava leaves } & \multicolumn{2}{|c|}{ Cinnamon } & \multicolumn{2}{|c|}{ Garlic } & \multicolumn{2}{|c|}{ Ginger } \\
\hline & Aqueous & Ethanol & Aqueous & Ethanol & Aqueous & Ethanol & Aqueous & Ethanol \\
\hline $\mathrm{I}_{1}$ & 40 & 36 & 20 & 41 & - & 20 & - & \\
\hline $\mathrm{I}_{2}$ & - & 30 & 23 & 46 & 19 & 44 & - & - \\
\hline $\mathrm{I}_{3}$ & - & - & 21 & 40 & 18 & - & - & - \\
\hline $\mathrm{I}_{4}$ & - & - & 19 & 45 & - & - & - & - \\
\hline$I_{5}$ & - & - & - & 46 & 37 & - & 15 & - \\
\hline
\end{tabular}

(-) means no inhibition; least significant differences (LSD) at $5 \%$ between isolates-3.0; LSD at $5 \%$ between plants extract- 5.9

July-August $2021 \quad$ Indian Journal of Pharmaceutical Sciences 
fig. 1A-1D. Therefore, MIC against isolate 2 of A. fumigatus was determined using these two plant extracts. Table 3 has illustrated MIC for garlic and cinnamon against isolate 2 of $A$. fumigatus, after incubation of $48 \mathrm{~h}$. The table shows that MIC of $2 \mathrm{mg} / \mathrm{ml}$ ethanol extract of garlic and cinnamon with inhibition zones of 17 and $20 \mathrm{~mm}$ respectively. Moreover, MIC of aqueous extract of garlic was $40 \mathrm{mg} / \mathrm{ml}$ with $18 \mathrm{~mm}$ of inhibition diameter; whereas, MIC of aqueous extract of cinnamon was $10 \mathrm{mg} / \mathrm{ml}$ with $11 \mathrm{~mm}$ of inhibition diameter.

Majority of the dreadful diseases whether animal or plant are controlled using economically essential medicinal plants. The present study has evaluated the inhibitory effect of alcoholic and aqueous extracts of ginger, garlic, cinnamon and guava against the isolates of $A$. fumigatus. There was a difference in the degrees of inhibition among the four plant extracts; however, isolates 1 and 2 were affected by ethanol extract of guava leaves. Resistance was shown by all the

TABLE 2: ANTIFUNGAL ACTIVITY OF THE TESTED PLANTS AGAINST ISOLATE 2 OF $A$. fumigatus AFTER EXTRACTION WITH DIFFERENT SOLVENTS

\begin{tabular}{lccc}
\hline \multirow{2}{*}{ Solvents } & \multicolumn{3}{c}{ Diameter of inhibition zone $(\mathrm{mm})$} \\
\cline { 2 - 4 } & \multicolumn{3}{c}{ Plant extracts } \\
& Guava leaves & Cinnamon & Garlic \\
\hline Ethanol & 23 & 47 & 43 \\
Methanol & 17 & 41 & 10 \\
Chloroform & - & 28 & 7 \\
Ethylacetate & 22 & 40 & 30 \\
\hline
\end{tabular}

(-) means no inhibition; LSD at $5 \%$ between plants extract-5.2; LSD at $5 \%$ between solvents- 6.0 isolates against aqueous and ethanol extract of ginger. Antifungal activity is exhibited by all the prepared water and ethanol cinnamon extracts against the isolates of A. fumigatus. This finding stated that inhibitory effect of cinnamon ethanol extract for the isolates was in line with the study conducted by Rodriguez et al. ${ }^{[29]}$. The results demonstrated that antimicrobial activity against Rhizopus stolonifer and Fusarium oxysporum (F. oxysporum) f. sp. lycopersici (Sacc) was presented in the presence of various aqueous and alcohol extracts/ essential oil distillates.

Previous studies have also exhibited antimicrobial activity of aqueous cinnamon extract for F. culmorum Sacc, F. oxysporum, A. niger, Alternaria alternate, along with some hydrolytic enzymes ${ }^{[30,31]}$. These hydrolytic enzymes include pectin, protease, lyase and Beta-glucosidase. Similarly, the activity of Syzygium, Cymbopogon and Cinnamomum species against Trichophyton rubrum (T. rubrum) and A. fumigatus was reported by Khan and Ahmad ${ }^{[32]}$. Similar to the present study, cinnamon was proved to be effective against some species of toxicogenic fungi and respiratory tract pathogens.

The results of present study showed that antifungal activity against $A$. fumigatus isolates was exhibited by aqueous and ethanol garlic extracts. These results were consistent with the study conducted by Natheer ${ }^{[33]}$. The study exhibited strong inhibitory effect by diethyl ether extract of cinnamon for the tested bacteria and Candida albicans ( $C$. albicans). Nevertheless, the antifungal activities of the ethanol extract of Zingiber officinale, mycelial dry weight and Annona muricata,

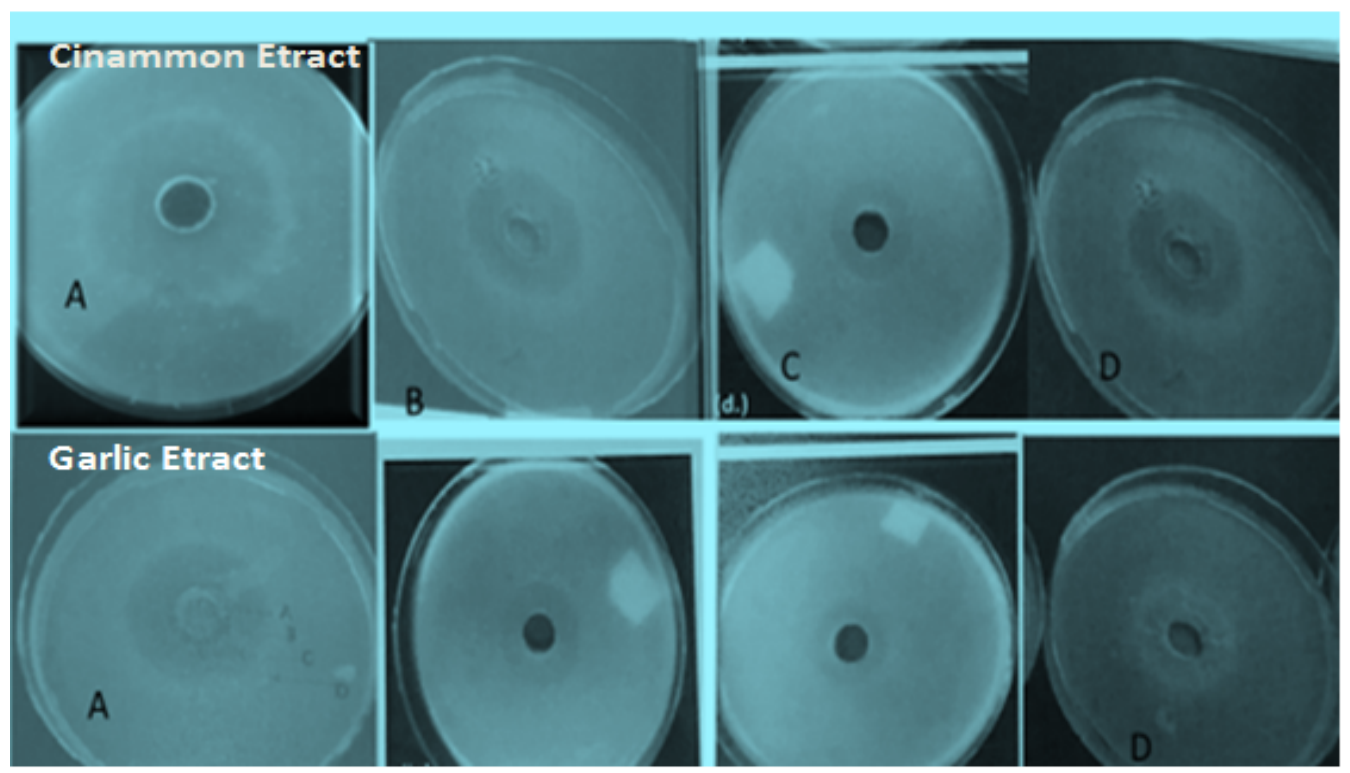

Fig. 1: Inhibitory activity of the different solvent extracts of cinnamon and garlic against $A$. fumigatus $\mathbf{I}_{2}$ (A) ethanol; (B) methanol; (C) chloroform; (D) ethylacetate 
www.ijpsonline.com

TABLE 3: MIC OF GARLIC AND CINNAMON EXTRACTS AGAINST ISOLATE 2 OF A. fumigatus

\begin{tabular}{|c|c|c|c|c|c|c|c|}
\hline \multirow{2}{*}{\multicolumn{2}{|c|}{ Plant extracts }} & \multicolumn{6}{|c|}{$\begin{array}{c}\text { Inhibition zone }(\mathrm{mm}) \\
\text { Concentrations }(\mathrm{mg} / \mathrm{ml})\end{array}$} \\
\hline & & 1 & 2 & 6 & 10 & 20 & 40 \\
\hline \multirow{3}{*}{ Cinnamon } & Aqueous & - & - & - & 11 & 12 & 13 \\
\hline & Ethanol & - & 20 & 24 & 30 & 32 & 35 \\
\hline & Aqueous & - & - & - & - & - & 18 \\
\hline Garlic & Ethanol & - & 17 & 20 & 22 & 23 & 25 \\
\hline
\end{tabular}

Alchornea cordifolia, Garcinia cola and Allium sativum against the mycelial elongation of Rhizopus stolonifer, Botrydiplodia theobromae, A. niger, F. solani and F. oxysporum was reported by Amienyo and Ataga ${ }^{[34]}$.

Similar to the results presented in the present study, Dhiman et al. ${ }^{[35]}$ showed that inhibition in growth of Escherichia coli, Pseudomonas aeruginosa, Staphylococcus aureus, A. niger and C. albicans was due to the effect of methanolic extract of Psidium guajava (P. guajava) using paper disc diffusion method. However, Rathish and Sumitra ${ }^{[36]}$ had stated inactivity of extracts of $P$. guajava against $A$. flavus, $A$. niger and A. candidus.

The present study has tested different solvents for selecting the most effective one, along with the ethanolic extract and presented high antifungal activity of cinnamon, garlic and guava ethanolic extract against isolate 2 of $A$. fumigatus. The ethanol extracts were considered to be powerful inhibitor, as compared to the extracts of methanol and chloroform. These results were similar to a previous study conducted by Senhaji et al ${ }^{[37]}$ showing active antimicrobial potential of ethanolic and hexanic extracts of cinnamon, as compared to other solvent extracts. On the contrary, antimicrobial activity was shown by methanol extract of C. zeylanicum towards microorganisms ${ }^{[38]}$.

The morphological changes taking place within the endomembrane structures and cell membrane of A. fumigatus and T. rubrum were observed by Khan and Ahmad $^{[32]}$ using electron light microscope after being treated with cinnamon oil. Cinnamon and other oils exhibited inhibitory effects against the synthesis of cell membrane and cell wall. The cell membrane along with other endomembrane structures of the cell was the primary target of oils; however, synthesis of cell wall was required due to disruption of cell membrane and other associated enzymes. The growth of microorganism is likely to be inhibited by cinnamaldehyde, which is a highly electronegative compound interfering with the biological processes that involve electron transfer and reaction with nitrogen containing compounds.
This study has determined MIC based on the preparation procedure used by Gayoso et al. ${ }^{[28]}$ undertaking different concentrations of either ethanol extract or hot water extract of both garlic and cinnamon. These concentrations include 1, 2, 6, 10, 20 and $40 \mathrm{mg} / \mathrm{ml}$, the plates were incubated at $28^{\circ}$ and after measuring the diameters of inhibition zone and the inhibitory activity was followed. Inhibition zone equal to $10 \mathrm{~mm}$ or more was considered for the MIC, which shows the lowest concentration $^{[39,40]}$.

The present study has investigated the antifungal activity of ethanol and aqueous extract against the opportunistic fungus $A$. fumigatus. The results showed inhibitory effect of ethanol extract of cinnamon, as compared to ginger, garlic and guava extracts. Therefore, it has been concluded that ethanol extracts of cinnamon can be used as antimycotic agent against A. fumigatus to treat diseases, rather than using chemical drugs having side effects. The use of natural products for treating various diseases is considered to be cheap, safe and ecofriendly source that reduce the complications and hazards of using chemical drugs. The study has suggested determining the sensitivity of fungal isolate to cinnamon extract before using it as different responses are provided by isolates in a wide range of extracts.

\section{Acknowledgements:}

The authors are very thankful to all the associated personnel in any reference that contributed in/for the purpose of this research.

\section{Conflict of interests:}

The authors declared no conflicts of interest.

\section{REFERENCES}

1. Greenberger PA. Allergic bronchopulmonary aspergillosis. J Allergy Clin Immunol 2002;110(5):685-92.

2. Pfaller MA, Diekema DJ. Rare and emerging opportunistic fungal pathogens: concern for resistance beyond Candida albicans and Aspergillus fumigatus. J Clin Microbiol 2004;42(10):4419-31.

3. O'Gorman CM, Fuller HT, Dyer PS. Discovery of a sexual 
cycle in the opportunistic fungal pathogen Aspergillus fumigatus. Nature 2009;457(7228):471-4.

4. Ebani VV, Najar B, Bertelloni F, Pistelli L, Mancianti F, Nardoni $\mathrm{S}$. Chemical composition and in vitro antimicrobial efficacy of sixteen essential oils against Escherichia coli and Aspergillus fumigatus isolated from poultry. Vet Sci 2018;5(3):62.

5. Beernaert LA, Pasmans F, van Waeyenberghe L, Haesebrouck F, Martel A. Aspergillus infections in birds: a review. Avian Pathol 2010;39(5):325-31.

6. Arné P, Thierry S, Wang D, Deville M, Loc'h L, Desoutter A, et al. Aspergillus fumigatus in poultry. Int J Microbiol 2011;2011.

7. Haiduven D. Nosocomial aspergillosis and building construction. Med Mycol 2009;47:210-6.

8. Correa-Royero J, Tangarife V, Durán C, Stashenko E, MesaArango A. In vitro antifungal activity and cytotoxic effect of essential oils and extracts of medicinal and aromatic plants against Candida krusei and Aspergillus fumigatus. Rev Bras Farmacogn 2010;20:734-41.

9. Gallien S, Fournier S, Porcher R, Bottero J, Ribaud P, Sulahian A, et al. Therapeutic outcome and prognostic factors of invasive aspergillosis in an infectious disease department: a review of 34 cases. Infection 2008;36(6):533-8.

10. Snelders E, van der Lee HA, Kuijpers J, Rijs AJ, Varga J, Samson RA, et al. Emergence of azole resistance in Aspergillus fumigatus and spread of a single resistance mechanism. PLoS Med 2008;5(11):e219.

11. van der Linden JW, Jansen RR, Bresters D, Visser CE, Geerlings SE, Kuijper EJ, et al. Azole-resistant central nervous system aspergillosis. Clin Infect Dis 2009;48(8):1111-3.

12. Abad MJ, Ansuategui M, Bermejo P. Active antifungal substances from natural sources. Arkivoc 2007;7(11):6-145.

13. Khalil MY, Moustafa AA, Naguib NY. Growth, phenolic compounds and antioxidant activity of some medicinal plants grown under organic farming condition. World J Agric Res 2007;3(4):451-7.

14. Sumathi P, Parvathi A. Antimicrobial activity of some traditional medicinal plants. J Med Plant Res 2010;4(4):316-21.

15. Pirbalouti AG, Hamedi B, Abdizadeh R, Malekpoor $F$. Antifungal activity of the essential oil of Iranian medicinal plants. J Med Plant Res 2011;5(20):5089-93.

16. Mann A, Banso A, Clifford LC. An antifungal property of crude plant extracts from Anogeissus leiocarpus and Terminalia avicennioides. Tanzan J Health Res 2008;10(1):34-8.

17. Carmo ES, Lima ED, Souza EL, Sousa FB. Effect of Cinnamomum zeylanicum blume essential oil on the rowth and morphogenesis of some potentially pathogenic Aspergillus species. Braz J Microbiol 2008;39:91-7.

18. Hosseini DR, Saberi M, Hoseini MJ, Mohabati MA. Surveillance of current antibiotic resistance among clinical isolates $S$. aureus, E. coli and $P$. aeroginosa collected from five Iranian cities. J Pharm Health Sci 2013;1:175-83.

19. Kalemba DA, Kunicka A. Antibacterial and antifungal properties of essential oils. Curr Med Chem 2003;10(10):81329.

20. Tajehmiri A, Rahmani MR, Moosavi SS, Davari K, Ebrahimi SS. Antifungal effects of six herbal extracts against Aspergillus sp. and compared to amphotericin B and nystatin. Int J Adv Appl Sci 2018;5(7):53-7.

21. Pfaller MA, Diekema DJ, Merz WG. Infections caused by non-
Candida, non-Cryptococcus yeasts. Clin Mycol 2009;10:25170.

22. Teles F, Seixas J. The future of novel diagnostics in medical mycology. J Med Microbiol 2015;64(4):315-22.

23. Raper KB, Fennell DI. The genus Aspergillus 1965.

24. El-Shafie AK. Soil fungi in Qatar and other Arab countries. Econ Bot 1996;50(2):242.

25. Varghes HP. Blood and urine Urea. Biochemistry Gulab Vazirani, New Delhi 1976:156-67.

26. Hoque MM, Inatsu M, Juneja V, Kawamoto S. Antimicrobial activity of cloves and cinnamon extracts against food borne pathogens and spoilage bacteria and inactivation of Listeria monocytogenes in ground chicken meat with their essential oils. Food Res Inst 2008;72:9-21.

27. Hadacek F, Greger H. Testing of antifungal natural products: methodologies, comparability of results and assay choice. Phytochem Anal 2000;11(3):137-47.

28. Gayoso CW, Lima EO, Souza EL. Inhibitory action of the essential oil of Cinnamomum zeylanicum Blume, $\alpha$-pinene and $\beta$-pinene on fungi isolated from onychomycosis. J Bras Fitomed 2004;1:25-9.

29. Rodriguez A, Nerín C, Batlle R. New cinnamon-based active paper packaging against Rhizopus stolonifer food spoilage. J Agric Food Chem 2008;56(15):6364-9.

30. Magro A, Carolino M, Bastos M, Mexia A. Efficacy of plant extracts against stored products fungi. Rev Iberoam Micol 2006;23(3):176-8.

31. Fawzi EM, Khalil AA, Afifi AF. Antifungal effect of some plant extracts on Alternaria alternata and Fusarium oxysporum. Afr J Biotechnol 2009;8(11).

32. Khan MS, Ahmad I. In vitro antifungal, anti-elastase and antikeratinase activity of essential oils of Cinnamomum-, Syzygiumand Cymbopogon-species against Aspergillus fumigatus and Trichophyton rubrum. Phytomedicine 2011;19(1):48-55.

33. Natheer SE. Antimicrobial and biochemical analysis of some spices extract against food spoilage pathogens. Internet J Food Saf 2010;12:71-5.

34. Amienyo CA, Ataga AE. Use of indigenous plant extracts for the protection of mechanically injured sweet potato [Ipomoea batatas (L.) Lam] tubers. Sci Res Essay 2007;2(5):167-70.

35. Dhiman A, Nanda A, Ahmad S, Narasimhan B. In vitro antimicrobial activity of methanolic leaf extract of Psidium guajava L. J Pharm Bioallied Sci 2011;3(2):226.

36. Nair R, Chanda S. In vitro antimicrobial activity of Psidium guajava L. leaf extracts against clinically important pathogenic microbial strains. Braz J Microbiol 2007;38:452-8.

37. Senhaji O, Faid M, Elyachioui M. Antibiosis by cinnamon extracts against antibiotic resistant strains. Int J Agric Biol 2005;7(5):724-8.

38. Keskin D, Toroglu S. Studies on antimicrobial activities of solvent extracts of different spices. J Environ Biol 2011;32(2):251-6.

39. Stangarlin JR, Schwan-Estrada KR, Cruz MD, Nozaki MH. Plantas medicinais e controle alternativo de fitopatógenos. Biotecnolog Cienc Desenvolv 1999;11(3):16-21.

40. Lima ED, Gompertz OF, Giesbrecht AM, Paulo MD. In vitro antifungal activity of essential oils obtained from officinal plants against dermatophytes. Mycoses 1993;36(9-10):333-6. 